\title{
TOUGH TIMES
}

\section{Dear Reader,}

this March was Audi's target date for delivery of the first R8 e-tron. It symbolised the advent of Ingolstadt's first electrically driven sports car and was supposed to usher in the e-car era at Audi. 100 vehicles at a price estimated by insiders to be around 200,000 euro. The OEM pulled out shortly before the launch.

The target customers in this premium segment are not concerned with money; they want high-tech and they want to be among the first of only a few owners. Despite that, according to statements by Audi, it was the high battery costs that caused Head of Development Wolfgang Dürheimer to pull the plug. His courage might also have failed him because of the batteries' unproven long-term stability.

"We are continuing where others have bowed out” said Dr. Thomas Weber, with a sideswipe at Audi. The Daimler Executive Vice President of Development is paying a heavy price for the imponderability of the battery in the Mercedes AMG SLS E-cell with a now confirmed 417,000 euro price tag for the Audi counterpart. The bottom line is a 200,000 euro premium for the electric variant of the gull-wing vehicle. It should now finally be available as of June following several postponements to the start of production. True, Audi is taking another look at the R8 e-tron's cost recovery but its withdrawal was certainly telling and heavy with symbolism. The price of the lithium-ion batteries is not going to change.

Only 250 euro for a kilowatt hour? You need look no further than this aspiration to understand the thinking because the goal of cutting costs threefold was originally announced for a time when e-cars would be coming off the production line in their thousands.
But until that day arrives, the name of the game is to gather experience with smaller production runs. For the time being, cost recovery is a pipe dream that may sound harsh but it reflects what numerous experts questioned by ATZelektronik in recent months have been saying.

The crucial learning phase is being underestimated, gaining experience is priceless is the message we are getting from automotive developers, electronics experts, chemists and materials scientists and last but not least manufacturing specialists and process engineers who need to cut their teeth on larger production runs.

ATZelektronik has been monitoring this process for years. This critical perspective may be grist to the mill of the electro-mobility sceptics but these ongoing tough times may prove to be more readily overcome with a greater dose of realism.

I wish everyone the best of success.

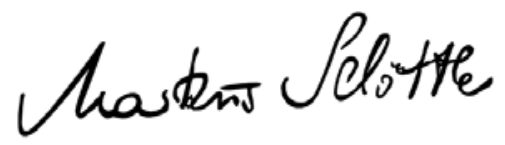

MARKUS SCHÖTTLE, Vice-Editor-in-Chief Wiesbaden, 04 March 2013

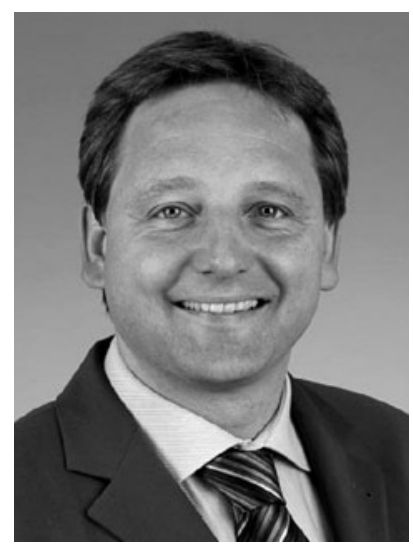

